\title{
Factors Associated with Disaster Response Competency of Nursing Students in Graduation Years
}

\author{
Do-Young Lee ${ }^{1}$, Gie-Ok Noh ${ }^{2}$ \\ ${ }^{1}$ Assistant Professor, Department of Nursing, Changshin University, 262 Palyongro, Masanhoewon-gu, Changwon- \\ si, Gyeongsangnam-do, 51352, South Korea, ${ }^{2}$ Assistant Professor, Department of Nursing, Konyang University, \\ 158 Kwanjeodongro, Seo-gu, Daejeon, 35365, South Korea
}

\begin{abstract}
Background: This study was conducted to provide the basis for the disaster nursing curriculum through grasping the degree of disaster preparedness attitude and disaster response competency of the senior nursing student.

Method: Data was collected through a questionnaire for senior nursing students from five universities in South Korea. A total of 168 data were analyzed through the IBM SPSS 25.0 program.

Finding: Disaster response competency were most strongly predicted by "satisfied" major satisfaction, followed by "average" major satisfaction, "realization of good deeds" motivation, "yes" experience of disaster education. The explanatory power by these variables was $19.7 \%$.

Conclusion: The results of this study suggested that the experience of disaster education is important to improve the disaster response competency of nursing students. In preparation for disasters that are unpredictable and lead to serious resource shortages, nursing colleges will have to make efforts to provide sufficient education and training.
\end{abstract}

Keywords: Disaster, Graduation, Nursing students, Preparedness attitude, Response competency.

\section{Introduction}

Disasters result in numerous human and property loss, and even extreme stress and health problems for contemporaries who experience them indirectly ${ }^{1}$. In Korea, the establishment of a national disaster management system since 1995 has led to a multidisciplinary interest in disaster-related research, which is no exception in the field of nursing 2,3 . Disaster education in Korean nursing began in 2005 at the Armed Forces Nursing Academy, and disaster nursing

\section{Corresponding Author:}

\section{Gie Ok Noh, PhD}

Assistant Professor, Department of Nursing, Konyang University, 158 Kwanjeodongro, Seo-gu, Daejeon, 35365, South Korea e-mail: nkorn91@gmail.com

Mobile: 82-10-3586-2239 is also operated with a large proportion ${ }^{4}$. There are also survey items on disaster management in the certification assessment standards of medical institutions, and we strive to improve nurses' disaster nursing competency by conducting regular disaster training and training on our own ${ }^{5}$. However, disaster preparedness education for nurses is partially conducted, and disaster preparedness education for nursing colleges is insufficient ${ }^{6}$. Disaster nursing is the systematic use of professional knowledge and skills to provide the nursing activities required by the subject to reduce the risk of life and health caused by the disaster ${ }^{7}$. In the event of a disaster, the need for medical workforce increases, so there should be a vast and diverse workforce suitable for the response system according to the magnitude of the damage ${ }^{3}$. In this respect, nurses should have attitudes and competency to various possible disasters. In order for nurses to be able to prepare for disaster situations, the nursing curriculum needs to include disaster competency training ${ }^{8}$, but most universities still address disaster nursing partially in 
some subjects such as emergency care and community care $^{6}$.

Nurses play a very important role as severity classification and first aid providers, care providers and mental health counselors at a time when there is a growing demand for health care due to many patients in the event of a disaster ${ }^{9}$. However, nurses were reported to have insufficient experience in disaster-related education and low disaster response competency ${ }^{10,11}$. Because disasters occur unexpectedly and cannot be learned directly from experience, disaster response competency requires systematic education and training in advance, which is necessary from nursing students when basic education begins ${ }^{12,13}$.

Therefore, this study aims to provide basic data for the development of disaster nursing education courses and programs by identifying disaster preparedness attitude and disaster response competency for the senior nursing students and identifying factors affecting disaster preparedness.

\section{Method}

Study Design: This study is a correlation survey study attempted to identify the disaster preparedness attitude and competency of the senior nursing student and to identify the factors affecting the disaster response complication.

Participants: The subjects of this study were students in the fourth grade (graduation grade) who were attending the nursing department of five domestic universities. The number of samples was calculated as significant level .05 , power .95 , effect size 0.15 and predictors 8 , referring to the preceding study of disaster experience and disaster preparedness of nursing students ${ }^{14}$. Using the $G^{*}$ power 3.1 .9 program $^{15}$, the minimum number of samples required for regression was 160 .

Measurements: The disaster preparedness attitude was measured by a tool developed by Moabi ${ }^{16}$. This tool consists of a total of 11 items, and four negatives were reversed. The higher the score on the Likert 5-point scale, the better disaster preparedness attitude. At the time of tool development, the reliability of Cronbach's $\alpha$ was .82 and the reliability of the instrument as assessed by Cronbach's alpha was .78 in the study. The disaster response competency was measured by $\mathrm{Huh}^{17}$ as well as the contents provided in ICN Disaster Nursing
Capacity Framework ${ }^{18}$ and the nurse's disaster response tool developed by An et al. ${ }^{10}$. The tool consists of four sub-regions: disaster prevention (6items), disaster response (7items), disaster copy (10items), and disaster rehabilitation and recovery (3items) total 26 items. The higher score on the Likert 5-point scale, the higher the disaster response competency. In Hu's study ${ }^{17}$, the reliability of Cronbach's $\alpha$ was .92 , and in this study the reliability of Cronbach's $\alpha$ was .96 .

Data Collection: Datawere selected from September 10 through October 15, 2020. For data collection, the purpose, procedures and method of this study were first explained to the director of the nursing college and then the survey was approved. Using the online questionnaire, we explained the purpose and method of the study and collected data from those who agreed to participate in the study. Online questionnaires were distributed in the form of access URLs via SNS of senior nursing students from five universities who had obtained consent to the survey. An anonymous questionnaire was used that did not include identifiable personal information.

Statistical Analysis: The data was analyzed using IBM SPSS 25.0. Of the 177 questionnaires returned, 9 questionnaires were excluded for having missing data. General characteristics, disaster preparedness attitude and competency were analyzed using frequency, percentage, mean, and standard deviation. The differences in disaster response competency according to characteristics were analyzed using independent t-tests or one-way ANOVA with Scheffé test for post-hoc analysis. The correlations between disaster preparedness attitude and disaster response competency were analyzed using Pearson's correlation coefficient. The factors associated with disaster response competency were analyzed using a step-wise multiple regression analysis.

\section{Results}

\section{Characteristics and disaster response competency of nursing students in graduation years} Female students accounted for $87.5 \%$ and $79.8 \%$ of those under the age of 25 , with $96.4 \%$ showing more than average major satisfaction. Because of the good employment, nursing was the most common choice of department, and $69.0 \%$ said they were healthy. $85.7 \%$ had experience in disaster education, and most (97.0\%) were aware of the need for disaster education (Table 1).

Disaster response competency has been found to be significantly high for those who show satisfaction with 
their majors $(\mathrm{F}=14.12, \mathrm{p}<0.001)$, those who have chosen nursing for their Realization of good needs $(\mathrm{F}=3.29$, $\mathrm{p}=0.013$ ), those who have experience in disaster education ( $\mathrm{t}=2.80 ; \mathrm{p}=0.006)$, and those requiring disaster education $(\mathrm{t}=2.45, \mathrm{p}=0.016)$.

Table 1: Characteristics and disaster response competency of participants $(n=168)$

\begin{tabular}{|c|c|c|c|c|}
\hline \multirow{2}{*}{ Characteristics } & \multirow{2}{*}{ Categories } & \multirow{2}{*}{ n (\%) } & \multicolumn{2}{|c|}{ Disaster response competency } \\
\hline & & & $\mathbf{M} \pm \mathbf{S D}$ & t or F (p) \\
\hline Gender & $\begin{array}{l}\text { Male } \\
\text { Female }\end{array}$ & $\begin{array}{r}21(12.5) \\
147(87.5)\end{array}$ & $\begin{array}{l}76.24 \pm 24.11 \\
85.95 \pm 15.09\end{array}$ & $-1.80(0.086)$ \\
\hline Age (yr) & $\begin{array}{l}<25 \\
\geq 25\end{array}$ & $\begin{array}{c}134(79.8) \\
34(20.2)\end{array}$ & $\begin{array}{l}86.14 \pm 14.41 \\
79.18 \pm 23.13\end{array}$ & $1.68(0.102)$ \\
\hline Major satisfaction & $\begin{array}{l}\text { Unsatisfied }^{\mathrm{a}} \\
\text { Average }^{\mathrm{b}} \\
\text { Satisfied }^{\mathrm{c}}\end{array}$ & $\begin{array}{c}6(3.6) \\
54(32.1) \\
108(64.3)\end{array}$ & $\begin{array}{l}54.33 \pm 22.60 \\
82.24 \pm 15.47 \\
87.67 \pm 15.15\end{array}$ & $\begin{array}{c}14.12(<0.001) \\
\mathrm{a}>\mathrm{b}, \mathrm{c}^{*}\end{array}$ \\
\hline $\begin{array}{l}\text { Motivation for choosing } \\
\text { the department of nursing }\end{array}$ & $\begin{array}{l}\text { High school grades }{ }^{a} \\
\text { Aptitude }^{b} \\
\text { Accessible job }^{c} \\
\text { Recommendation }^{d} \\
\text { Realization of good deeds }^{\text {e }}\end{array}$ & $\begin{array}{c}13(7.7) \\
41(24.4) \\
75(44.6) \\
27(16.1) \\
12(7.1)\end{array}$ & $\begin{array}{l}75.00 \pm 20.40 \\
83.93 \pm 14.05 \\
85.59 \pm 14.48 \\
82.48 \pm 20.09 \\
97.75 \pm 19.60\end{array}$ & $\begin{array}{c}3.29(0.013) \\
\mathrm{a}<\mathrm{e}^{*}\end{array}$ \\
\hline Heath status & $\begin{array}{l}\text { Good } \\
\text { Moderate } \\
\text { Bad }\end{array}$ & $\begin{array}{c}116(69.0) \\
45(26.8) \\
7(4.2)\end{array}$ & $\begin{array}{l}84.96 \pm 17.34 \\
84.16 \pm 15.53 \\
84.57 \pm 15.21\end{array}$ & $0.04(0.963)$ \\
\hline $\begin{array}{l}\text { Experience of disaster } \\
\text { education }\end{array}$ & $\begin{array}{l}\text { Yes } \\
\text { No }\end{array}$ & $\begin{array}{c}114(85.7) \\
24(14.3)\end{array}$ & $\begin{array}{l}86.17 \pm 16.98 \\
76.08 \pm 11.91\end{array}$ & $2.80(0.006)$ \\
\hline Need for disaster education & $\begin{array}{l}\text { Yes } \\
\text { No }\end{array}$ & $\begin{array}{c}163(97.0) \\
5(3.0)\end{array}$ & $\begin{array}{l}85.28 \pm 16.56 \\
67.00 \pm 11.66\end{array}$ & $2.45(0.016)$ \\
\hline
\end{tabular}

* Scheffé post hoc

Disaster preparedness attitude and disaster response competency of participants: The disaster preparedness attitude of the graduate nursing college student was confirmed to be $38.77 \pm 3.95$ points on average on a scale of 44 points. The disaster response competency averaged $84.73 \pm 16.70$ points on a total score of 130 points. In the lower section, the competency for disaster rehabilitation and recovery was found to be the highest level (Table 2).

Table 2: Disaster preparedness attitude and disaster response competency of participants $(n=168)$

\begin{tabular}{|l|c|c|c|c|}
\hline Scale items & Number of items & Possible score range & Mean \pm SD & $\begin{array}{c}\text { Mean } \pm \text { SD } \\
\text { Number of items }\end{array}$ \\
\hline Disaster preparedness attitude & 11 & $11-44$ & $38.77 \pm 3.95$ & $3.52 \pm 0.36$ \\
\hline Disaster response competency & 26 & $26-130$ & $84.73 \pm 16.70$ & $3.26 \pm 0.64$ \\
Prevention & 6 & $6-30$ & $19.57 \pm 4.36$ & $3.26 \pm 0.73$ \\
Preparedness & 7 & $7-35$ & $22.89 \pm 4.94$ & $3.27 \pm 0.71$ \\
Cope & 10 & $10-50$ & $32.07 \pm 6.72$ & $3.21 \pm 0.67$ \\
Rehabilitation and recovery & 3 & $3-15$ & $10.20 \pm 2.31$ & $3.40 \pm 0.77$ \\
\hline
\end{tabular}

Correlations between disaster preparedness attitude and disaster response competency: The higher level of disaster preparedness attitude of participants, the higher level of ability related to disaster prevention and recovery $(\mathrm{r}=20, \mathrm{p}=0.011 ; \mathrm{r}=.19, \mathrm{p}=0.012)$. Therefore, disaster preparedness has a significant amount of correlation with total disaster response competency $(\mathrm{r}=6.12, \mathrm{p}=6.02)$. 
Table 3: Correlations between disaster preparedness attitude and disaster response competency $(\mathrm{n}=168)$

\begin{tabular}{|l|c|c|c|c|c|}
\hline & $\begin{array}{c}\text { Disaster } \\
\text { prevention }\end{array}$ & $\begin{array}{c}\text { Disaster } \\
\text { preparedness }\end{array}$ & Disaster cope & $\begin{array}{c}\text { Disaster rehabilitation } \\
\text { and recovery }\end{array}$ & $\begin{array}{c}\text { Disaster response } \\
\text { competency }\end{array}$ \\
\cline { 2 - 6 } & $\mathbf{r}(\mathbf{p})$ & $\mathbf{r}(\mathbf{p})$ & $\mathbf{r}(\mathbf{p})$ & $\mathbf{r}(\mathbf{p})$ & $\mathbf{r}(\mathbf{p})$ \\
\hline Disaster preparedness attitude & $.07(0.354)$ & $.20(0.011)$ & $.13(0.084)$ & $.19(0.012)$ & $.16(0.042)$ \\
\hline
\end{tabular}

Factors associated with disaster response competency: In order to identify the factors influencing the disaster response competency of the senior nursing student, multiple regression analysis was conducted by injecting significant variables among the characteristics of the target and disaster preparedness attitude. The variables for Major satisfaction, motivation for choosing the department of nursing (motivation), experience of disaster education, need for disaster education were converted to dummy variables and statistical analysis was conducted. There were no problems with the autocorrelation (Durbin-Watson=1.742) and the multicollinearity (tolerance $=0.15-0.99 ; \mathrm{VIF}=1.01-6.82$ ) in the implementation of multi-recursive analysis.
The regression model was significant $(\mathrm{F}=11.29$, $\mathrm{p}<0.001$ ), and average to satisfied major satisfaction, choosing nursing major for realization of good deeds, experience of disaster education were found to be significant predictors of disaster response competency. The adjusted R2, indicating the model's explanatory power, was $19.7 \%$. Disaster response competency were most strongly predicted by "satisfied" major satisfaction $(\beta=0.97)$, followed by "average" satisfaction $(\beta=0.77)$, "realization of good deeds" motivation $(\beta=0.18)$, "yes" experience of disaster education $(\beta=0.18)$ (Table 4$)$.

Table 4: Factors associated with disaster response competency $(n=168)$

\begin{tabular}{|l|c|c|c|c|c|}
\hline Variables & B & SD & $\boldsymbol{\beta}$ & t & p \\
\hline Major satisfaction_satisfied $^{*}$ & 31.85 & 6.29 & 0.97 & 5.06 & $<0.001$ \\
\hline Major satisfaction_average $^{*}$ & 27.57 & 6.45 & 0.77 & 4.28 & $<0.001$ \\
\hline Motivation_realization of good deeds $^{*}$ & 11.90 & 4.50 & 0.18 & 2.65 & $<0.001$ \\
\hline Experience of disaster education $^{*}$ & 8.77 & 3.33 & 0.18 & 2.64 & $<0.001$ \\
\hline $\mathrm{R}^{2} /$ Adjusted R & & \multicolumn{5}{|c|}{$11.216 / .197$} \\
\hline $\mathrm{F}(p)$ & \multicolumn{5}{|c|}{$11.001)$} \\
\hline
\end{tabular}

*Dummy variable; Major satisfaction $(0=$ Unsatisfied $)$, Motivation $(0=$ High school grades $)$, Experience of disaster education $(0=$ No $)$

\section{Discussion}

In this study, in order to provide basic data on disaster preparedness, the disaster response competency and disaster preparedness attitude of the senior nursing student were identified and the influencing factors were presented. As participants in this study were fourth-grade nursing students ahead of graduation, their experience in disaster nursing education was confirmed by $85.7 \%$ who were higher than the preceding studies ${ }^{1,19}$. In addition, most $(97 \%)$ of those surveyed were aware of the need for disaster education. This is believed to be COVID-19, reflecting the present time in the infectious disaster situation, and to have shown a higher perception than the preceding studies ${ }^{1,19-20}$.
In this study, the disaster response competency according to general characteristics was found to be significantly higher if disaster education experience was present, if disaster education was required. In the preceding study ${ }^{6}$, disaster response competency was high if disaster-related education was received. Therefore, in order to enhance competency, it will be necessary to continuously provide disaster education.

In the disaster response competency of the senior nursing student, the competency for disaster rehabilitation and recovery was identified as the highest level in the sub-item. The study by Ann \& $\mathrm{Kim}^{1}$ said that in order to demonstrate disaster preparedness, one needs to be confident about one's ability through professional and 
specific education. A study by Huh \& Park $^{20}$ suggested the need for various aspects of education in disaster nursing subjects, including trauma treatment, severity classification, and the use of protective equipment. Therefore, the training of disaster response competency will require more enhanced training for those areas by first identifying insufficient capabilities. The higher the level of disaster preparedness attitude of the senior nursing student, the higher the level of disaster response competency. This supports the results of a prior study ${ }^{6}$ that presents factors affecting the ability to perform disaster nursing as a perception of disaster.

Finally, Disaster response competency were most strongly predicted by "satisfied" major satisfaction, followed by "average" average, "realization of good deeds" motivation, "yes" experience of disaster education. This is consistent with the presentation of the need for disaster education in many preceding studies $^{6,19,21}$ to enhance disaster response competency. Based on the research results, it can be suggested that disaster education be implemented as a realization of good needs through active participation and experience in nursing curriculum.

Although this study is meaningful in that it presents factors for improving disaster response competency, it is limited in generalizing the results because it involves limited participants. Further research is also required to verify additional variables affecting the disaster response competency, with the explanatory power of the variables identified in this study being low at $19.7 \%$.

\section{Conclusion and Recommendations}

This study is meaningful in that it identifies the attitude and competency of the senior nursing student to prepare for disasters and presents the factors that affect the disaster response competency. Based on the results, I propose an integrated education program of theory and practice that can improve the disaster response competency of nursing college students. It also suggests attempts for qualitative research about the awareness, demand and satisfaction of disaster education of nursing students.

Ethical Clearance: Not required

Source of Funding: This study was supported by Changshin University Research Fund of Changshin-2020-023.

\section{Conflicts of Interest: None}

\section{References}

1. Ahn EG, Kim SK. Disaster experience, perception and core competencies on disaster nursing of nursing students. The Journal of Digital policy \& management. 2013;11(6):257-267.

2. Lee $\mathrm{OH}$. Trends of nursing research on disasters in Korea. Journal of Korean Public Health Nursing. 2014;28(3): $432-444$.

3. Kim SY. Safety awareness and safety practice behavior of college students. Journal of Digital Convergence. 2015;13(2): 279-289.

4. The Korean Nurses Association News, Seoul. 2014. Secure Republic of Korea-checks the emergency care system. Available from: http://www.korea.kr/ archive/expDocView.do?docId $=38076 \&$ group $=\mathrm{D}$ [Accessed $1^{\text {st }}$ April 2015].

5. Korea Institute for Healthcare Accreditation. Available from: https://www.koiha.or.kr/web/kr/ library/establish board.do [Accessed 1 st November 2020].

6. Park AS. The effect of disaster awareness, attitude, preparedness on the basic competencies of disaster nursing among nursing students. Journal of the Korean Data Analysis Society. 2017;19(3): 16251636.

7. Lee YR, Lee MH, Park SK. Development of the disaster nursing competency scale for nursing students. Journal of the Korea society of disaster information. 2013;9(4): 511-520.

8. Mika S, Yoshiko N. Consideration of the contents of disaster-nursing education in basic nursing education: knowledge and practical abilities required for effective radiation-disaster Nursing. Hirosaki Medical Journal. 2019;69(1-4):44-56.

9. Arbon $\mathrm{P}$ et al. Exploring staff willingness to attend work during a disaster: A study of nurses employed in four Australian emergency departments. Australasian Emergency Nursing Journal. 2013;16(3): 103-109.

10. Ahn EG, Keum KL, Choi SY. A study on the disaster preparedness of nurses in some Korean regional emergency medical centers. Journal of Military Nursing Research. 2011;29(1): 94-109.

11. Hammad KS, Arbon P, Gebbie KM. Emergency nurses and disaster response: an exploration of South Australian emergency nurses' knowledge 
and perceptions of their roles in disaster response. Australasian Emergency Nursing Journal. 2011;14(2): 87-94.

12. Bouda K, Yokouchi M, Okada J, Fujimoto H, Nakanobu $\mathrm{R}$ et al. Education issues based on the results of disaster triage training for nursing students. Journal of Japan Society of Disaster Nursing. 2007;9(2): 25-39.

13. Susan A, Joy KK. Disaster preparedness; need for inclusion in undergraduate nursing education. Sultan Qaboos University Medical Journal. 2016;16(1):15-19.

14. Kang KH, Uhm D, Nam E. A study on disaster experience and preparedness of university students. The Journal of Korean Academic Society of Nursing Education. 2012;18(3): 424-435.

15. Faul F, Erdfelder E, Buchner A, Lang AG. Statistical power analyses using $G^{*}$ Power 3.1: tests for correlation and regression analyses. Behavior research method. 2009;41(4): 1149-1160.

16. Moabi RM. Knowledge, attitudes and practices of health care workers regarding disaster preparedness at Johannesburg hospital in Gauteng Province,
South Africa [Ph.D Thesis]. University of the Witwatersrand; 2008.

17. Huh SS. The effect of a disaster nursing education program on disaster nursing competency of nursing students: case based small group learning [Ph.D Thesis]. Chosun university; 2017.

18. World Health Organization and International Council for Nurses. ICN Framework of disaster nursing competencies. Geneva: 2009.

19. Kim HJ. A study on disaster preparedness, core competencies and educational needs on disaster nursing of nursing students. Journal of the Korea Academia-Industrial cooperation Society. 2015;16(11): 7447-7455.

20. Hur J, Park HJ. Nursing students' perception, competency of disaster nursing and ego resilience, Journal of Learner-Centered Curriculum and Instruction. 2015;15(8): 121-138.

21. Somjinda C, Wanpen I. Effects of an interactive teaching method on perceived disaster nursing competencies of undergraduate nursing students. Health Emergency and Disaster Nursing. 2018; 5(1):25-31. 